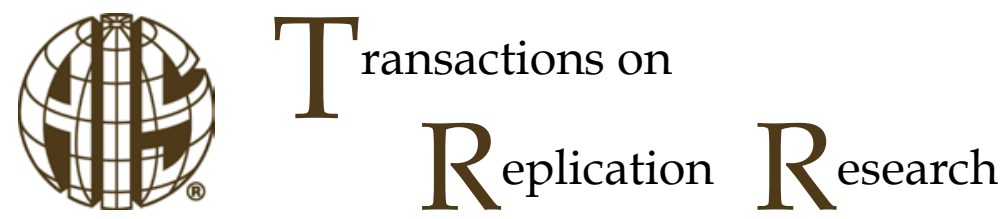

Methodological Replication

ISSN 2473-3458

\title{
Information System Continuance Intention in the Context of Network Effects and Freemium Business Models: A Replication Study of Cloud Services in Germany
}

\author{
Pascal Budner \\ University of Cologne, Cologne, Germany \\ pbudner@smail.uni-koeln.de \\ Mareike Fischer \\ University of Cologne, Cologne, Germany \\ mareike.fischer@wiso.uni-koeln.de \\ Dirk Basten \\ University of Cologne, Cologne, Germany \\ basten@wiso.uni-koeln.de \\ Christoph Rosenkranz \\ University of Cologne, Cologne, Germany \\ rosenkranz@wiso.uni-koeln.de \\ Lars Terlecki \\ University of Cologne, Cologne, Germany \\ Iterleck@smail.uni-koeln.de
}

\begin{abstract}
:
This paper reexamines the reasons for continued usage of information systems (IS), methodologically replicating a study by Bhattacherjee (2001) that investigates IS continuance by means of the expectation-confirmation model. For this purpose, the original research model was adapted and examined in a different context: cloud service usage in Germany, focusing on Dropbox. The conditions in a cloud service context differ fundamentally from those in the original study (online banking), since use is free of charge (freemium business models), customers have a wide choice of providers with low switching costs, and positive network effects are presumably in effect. The empirical analysis of 321 responses from a cross-sectional study based on the research model of Bhattacherjee (2001) confirmed his results for a different sample group and in a different context: confirmation was a predictor of perceived usefulness, satisfaction was significantly influenced by confirmation and perceived usefulness, and satisfaction and perceived usefulness predicted continuance intention. Nevertheless, the path coefficients of satisfaction and perceived usefulness on continuance intention were measurably lower in our results than in the original study. The findings imply that although the model is generally confirmed, additional factors are likely to influence the intention to continue IS usage in this specific context.
\end{abstract}

Keywords: IS Continuance Intention, IS Continuance Model, Expectation, Confirmation, Satisfaction, Perceived Usefulness, Freemium Business Models, Network Effects, Cloud Services, Structural Equation Modeling, Dropbox

The manuscript was received 10/31/2016 and was with the authors 5 months for 2 revisions. 


\section{Introduction}

Information system (IS) continuance describes the use of information systems beyond an initial acceptance phase, in which a consumer successfully decides to start using a product (Bhattacherjee, 2001). Deeper knowledge about the long-term usage of IS may be more important than initial acceptance, since the system provider benefits most from a sustained relationship (Bhattacherjee, 2001). As one of the first researchers that concentrated on IS continuance, Bhattacherjee (2001) introduced the expectationconfirmation model (ECM). The model is based on a combination of the technology acceptance model (TAM) (Davis, 1985) and the expectation-confirmation theory (Oliver, 1980). The ECM measures four constructs: (1) IS continuance intention, (2) satisfaction, (3) perceived usefulness and (4) confirmation (Bhattacherjee, 2001). By means of the ECM, Bhattacherjee (2001) delivered the first explanation for the acceptance-discontinuance anomaly, which occurs when consumers start using a system, but later decide to discontinue use.

The model has been extended and adopted in a variety of contexts by several researchers. For example, Limayem, Hirt, \& Cheung (2007) examined the influence of habits on IS continuance. They found that habits serve as a suppressor on continuance intention and thus limit its predictive power so that the inclusion of habit theory may explain derivations from the expected behavior. Lin, Wu, \& Tsai (2005) included perceived playfulness in the ECM for the web portal context. Their results suggest that perceived playfulness has a significant influence on continuance intention (Lin et al., 2005). Bhattacherjee (2001) has shown in his study that the predictors of initial IS adoption differ from those of IS continuance. Still, the ECM was often combined with theories explaining behavior in the acceptance phase, such as the Unified Theory of Acceptance and Use of Technology (UTAUT) (e.g., Chiu \& Wang, 2008) or TAM (e.g., Thong, Hong, \& Tam, 2006). Bhattacherjee \& Barfar (2011) state that the combination of acceptance and continuance theories might be inappropriate because the models predict two different behaviors in separate contexts.

A recent study by Vedadi \& Warkentin (2016) already replicated the original model and found that the IS continuance model is supported in a context of mobile banking applications. In this paper, we also reinvestigate (1) the salient motivations underlying user intention to continue using an IS after the initial acceptance phase and (2) the way in which these motivations have an influence on the continuance intention. Therefore, the ECM is used as a research model in accordance with the original paper. In addition, this study was changed to focus on usage of the cloud-service Dropbox in Germany to test the boundaries of the proposed theory in another context, which is strongly affected by freemium business models, low switching costs, and network effects.

Dropbox is an American file hosting service that mainly offers its customers cloud storage and file synchronization and has more than 500 million users worldwide ${ }^{1}$. The company uses a capacity-based freemium business model, where users are offered a free version with limited storage size (Kumar, 2014). The client software allows users to create a folder on their computers. The respective files are then automatically synchronized on all devices that have a Dropbox client installed and are linked to that folder. Moreover, synchronized folders can be shared with other users to simplify sharing of files and folders.

The cloud service Dropbox has been chosen as the object of our study because cloud services - in accordance with online banking in the original study - have gained importance and increased in prevalence in recent years. However, the specific characteristics of cloud services significantly differ from the original study's online banking context, in that cloud services have 1) low switching costs, (2) high competition, (3) freemium business models, and (4) positive network effects. These specific characteristics promise deeper insight into the continuance intention. First, a bank account is bound to an associated online banking application and, thus, switching to another service implies changing the bank account. In contrast, digital files can easily be transferred to another storage location. Thus, the switching costs for the customer in this cloud service industry are rather low and the intention to continue using the application could partly result from customers' concerns about high switching costs and inconvenience. Second, there are several competitors in the field of cloud storage providers offering similar features to Dropbox at very low or no cost (e.g., Microsoft OneDrive, Google Drive, Amazon Drive). As a result, the users who decide to discontinue using Dropbox can easily find an equivalent service. Third, both continuance and discontinuance of the service offered by Dropbox - as well as most of its competitors - is

\footnotetext{
${ }^{1}$ https://blogs.dropbox.com/dropbox/2016/03/500-million/ (Last visited 22/07/2017)
} 
free of charge in the basic version. This condition might increase a customer's willingness to begin or stop using a service and, therefore, affect the total number of switches between applications. Finally, we assume that positive network effects have an influence on continuance intention, which are present when the value or usefulness of a service increases with the number of users of the service (Shapiro \& Varian, 1999). For instance, Dropbox users benefit from an increasing number of users, since the more users Dropbox has, the larger the group of people with whom users can share files.

\section{Research Model and Hypotheses}

The purpose of this paper is to transfer the ECM model to different context. Methodologically, the same research model and hypotheses were used as in the original study. Theoretical considerations about deriving the hypotheses are further detailed in the original paper (Bhattacherjee, 2001). The underlying research model is presented in Figure 1 along with the results of the original study (Bhattacherjee, 2001).

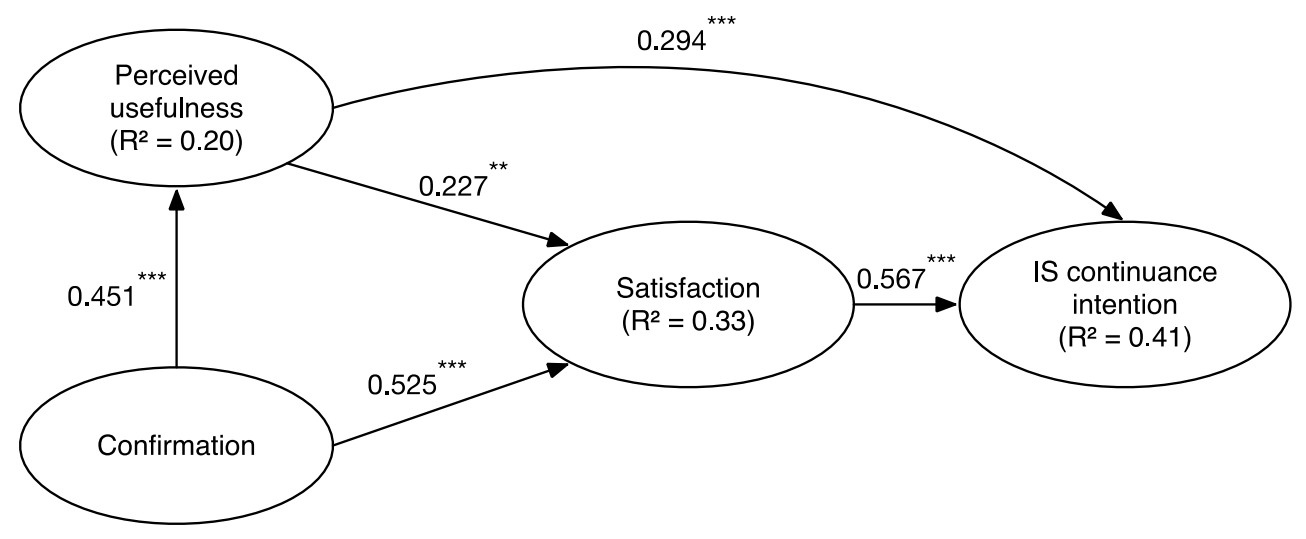

Figure 1. Expectation-Confirmation Model adapted from and presenting the EQS analysis of Bhattacherjee (2001) (Path significance: *** $\mathrm{p}<.001$, ** $\mathrm{p}<.01$ )

Bhattacherjee (2001) postulated and validated the following hypotheses:

Hypothesis 1: Users' level of satisfaction with initial IS use is positively associated with their IS continuance intention.

Hypothesis 2: Users' extent of confirmation is positively associated with their satisfaction with IS use.

Hypothesis 3: Users' perceived usefulness of IS use is positively associated with their satisfaction with IS use.

Hypothesis 4: Users' IS continuance intention is positively associated with their perceived usefulness of IS use.

Hypothesis 5: Users' extent of confirmation is positively associated with their perceived usefulness of IS use.

The study found that all hypotheses in the model were significant at $p<0.01$ (Bhattacherjee, 2001). The intention to continue using an IS was predicted by satisfaction $(\beta=0.57)$ and perceived usefulness $(\beta=$ 0.29 ), which explained $32 \%$ and $9 \%$ of the intention variance respectively. Via satisfaction, perceived usefulness additionally had a smaller indirect effect on the intention $(\beta=0.13)$ that explained $1.7 \%$ of the variance. Satisfaction itself was predicted by confirmation $(\beta=0.53)$ and perceived usefulness $(\beta=0.23)$ that explained $28 \%$ and $5 \%$ of the variance respectively. Accordingly, confirmation had a small indirect effect $(\beta=0.10)$ via perceived usefulness on satisfaction. Last, confirmation significantly predicted perceived usefulness $(\beta=0.45)$, which explained $20 \%$ of its variance. 


\section{Research Method}

\subsection{Replication Type}

Dennis \& Valacich (2014) classify replication studies into three distinct types: (1) exact replications, (2) methodological replications, and (3) conceptual replications. Exact replications use the exact same context and methods (i.e., measures, treatments, statistics, etc.). Methodological replications, in contrast, use the exact same methods but change the context to another group of respondents. Conceptual replications - as the strongest form of replication studies - test the same research questions and hypotheses, but use different methods and/or contexts (Dennis \& Valacich, 2014). This paper uses reworded questions, a changed context from online banking users to users of file hosting cloud services in Germany, and a switched software to implement and conduct the survey. Conversely, the same analysis method was used. This paper conforms to characteristics of both methodological and conceptual replications. However, since the requirements for conceptual replication studies, which are considered the superior replication type (Dennis \& Valacich, 2014), are not entirely fulfilled, we classify our study as a methodological replication.

\subsection{Data Collection}

In accordance with the original study, the empirical data for this replication study was collected using a cross-sectional field survey. However, unlike the original study, in which customers of one bank were surveyed, this study consulted Dropbox users that have mostly been recruited via Facebook (http://www.facebook.com). The invitation to participate in the survey has been published on the timeline of the authors of this paper and in several university-specific Facebook groups. The invitation message highlighted the purpose of this study, provided a hyperlink to the online survey, and underlined an incentive, which was inclusion in a lottery to win a 100 EUR voucher for Amazon.

The contents of the survey have been changed to focus on the file hosting cloud service Dropbox. This mitigates the sampling bias of the original study by expanding the scope of the respondents to a context in which network effects and low switching costs exist. Furthermore, the survivorship bias (Elton, Gruber, \& Blake, 1996) of the original study is mitigated by also addressing an audience that has stopped using Dropbox. The original study was limited to actual users of the online banking system to participate in their survey, since they recruited them via their monthly statement (Bhattacherjee, 2001). Respondents were instructed to complete the survey only if they had used Dropbox at least once.

Rejecting incomplete or invalid surveys led to 327 usable responses out of 387 in total. The respondents' age ranged from 18 to 57 with an average of 23.7 and a standard deviation of 4.8 . Respondents covered $54.7 \%$ males and $45.3 \%$ females. The monthly income ranged from 'no income' to 'more than 4,000 EUR' (mean of ' 500 EUR to 1,000 EUR'). Of the participants, $97 \%$ came from Germany, $88.4 \%$ were students, and $98 \%$ of all participants used the free Dropbox Basic version. However, $44 \%$ of those using Dropbox Basic upgraded their storage space for free by participating in marketing campaigns. Sixty-seven percent of the participants used more than one file hosting cloud service. The most frequently used file hosting cloud services besides Dropbox (97.9\%) were iCloud (34.6\%), Google Drive (31.5\%), and OneDrive (25.7\%). Appendix A provides further characteristics of the respondents.

\subsection{Measurements Development}

The measures used in this survey were adapted from the original study conducted by Bhattacherjee (2001). However, the wording of the items has been changed from focusing on online banking users to focusing on Dropbox users, all while ensuring that the modifications retained the original meanings of the measurements. Moreover, the language of the survey has been changed to German, since the target audience was German students. The translation from English to German has been validated by a bilingual native speaker living in Germany.

Accordingly, the four measured constructs-IS continuance intention (Cl), satisfaction (S), perceived usefulness (PU), and confirmation (C) - were measured using the same multiple-item scales but were reworded to relate to the use of Dropbox. Hence, satisfaction has been measured by a seven-point semantic differential scale, whereas the other constructs have been measured by a seven-point Likert scale. Table 1 shows these measures and their corresponding primary sources. The translated construct measurements can be found in Appendix B. 


\begin{tabular}{|c|c|c|}
\hline Construct & Measurement item & Adapted from \\
\hline Confirmation (C) & & \multirow{4}{*}{$\begin{array}{l}\text { Bhattacherjee } \\
\qquad(2001)\end{array}$} \\
\hline $\mathrm{C} 1$ & $\begin{array}{l}\text { My experience with using Dropbox was better } \\
\text { than what I expected. }\end{array}$ & \\
\hline $\mathrm{C} 2$ & $\begin{array}{l}\text { The service level provided by Dropbox was } \\
\text { better than what I expected. }\end{array}$ & \\
\hline $\mathrm{C} 3$ & $\begin{array}{l}\text { Overall, most of my expectations from using } \\
\text { Dropbox were confirmed. }\end{array}$ & \\
\hline \multicolumn{2}{|c|}{ Perceived Usefulness (PU) } & \multirow{5}{*}{ Davis (1989) } \\
\hline PU1 & $\begin{array}{l}\text { Using Dropbox improves my performance in } \\
\text { managing my files. }\end{array}$ & \\
\hline PU2 & $\begin{array}{l}\text { Using Dropbox improves my productivity in } \\
\text { managing my files. }\end{array}$ & \\
\hline PU3 & $\begin{array}{l}\text { Using Dropbox improves my effectiveness in } \\
\text { managing my files. }\end{array}$ & \\
\hline PU4 & $\begin{array}{l}\text { Overall, Dropbox is useful in managing my } \\
\text { files. }\end{array}$ & \\
\hline Satisfaction (S) & $\begin{array}{l}\text { How do you feel about your overall } \\
\text { experience of Dropbox use? }\end{array}$ & \multirow{5}{*}{$\begin{array}{c}\text { Spreng, } \\
\text { MacKenzie, \& } \\
\text { Olshavsky (1996) }\end{array}$} \\
\hline S1 & Very dissatisfied ... Very satisfied & \\
\hline S2 & Very frustrated ... Very contended & \\
\hline S3 & Very displeased ... Very pleased & \\
\hline S4 & Absolutely terrible ... Absolutely delighted & \\
\hline \multicolumn{2}{|c|}{ IS Continuance Intention (IS) } & \multirow{4}{*}{ Mathieson (1991) } \\
\hline $\mathrm{Cl}$ & $\begin{array}{l}\text { I intend to continue using Dropbox rather than } \\
\text { discontinue its use. }\end{array}$ & \\
\hline $\mathrm{Cl} 2$ & $\begin{array}{l}\text { My intentions are to continue using Dropbox } \\
\text { than use any alternative means. }\end{array}$ & \\
\hline $\mathrm{Cl} 3$ & $\begin{array}{l}\text { If I could, I would like to discontinue my use } \\
\text { of Dropbox. }\end{array}$ & \\
\hline
\end{tabular}

\section{Results}

\subsection{Measurement Validity}

In accordance with the original study, the measurement validity for the four constructs was measured by means of a confirmatory factor analysis (CFA) using SPSS AMOS version 24. Since the model of this paper agrees with the original study of Bhattacherjee (2001), the following four constructs were investigated: (1) IS continuance intention, (2) satisfaction, (3) perceived usefulness and (4) confirmation. The structural conditions were also similar to the original study: the scale items were modeled as a reflective indicator of their hypothesized latent constructs and the four constructs were allowed to co-vary in the CFA model. Moreover, the model estimation, performed by means of the maximum likelihood approach, with the item correlation matrix used as an input, was computed equally with the original study. For the analysis, only data from participants using the free Dropbox Basic version has been examined to avoid any bias from paying users. Initial descriptive statistics for the measurements of this study can be found in Appendix C.

As a first check for data quality an exploratory factor analysis (EFA) has been conducted to check the convergent and discriminant validity of the collected dataset. Two items (PU4 and C3) have been dropped during the EFA because they had low loadings or major cross-loadings between the factors. The component matrix that led to the removal of both items can be found in Appendix D, while Appendix $E$ contains a shortened structural equation modeling (SEM) analysis without dropping the items. Table 2 illustrates that after the item drop, convergent and discriminant validity are given by (1) the high loadings within the components and (2) that no critical cross-loadings between the components exist (the primary loading is at least 0.2 larger than the secondary loading). Moreover, an adequate internal consistency reliability is indicated, since each construct Cronbach's alpha exceeds the threshold of 0.7 (see Table 3). 


\begin{tabular}{|l|l|l|l|l|}
\hline \multicolumn{5}{|l|}{ Table 2. Discriminant Validity: Rotated Component Matrix } \\
\hline \multirow{3}{*}{ Item } & \multicolumn{3}{|l|}{ Component } \\
\cline { 2 - 5 } & Satisfaction & $\begin{array}{l}\text { Perceived } \\
\text { usefulness }\end{array}$ & $\begin{array}{l}\text { Continuance } \\
\text { Intention }\end{array}$ & Confirmation \\
\hline C1 & 0.224 & 0.119 & 0.235 & $\mathbf{0 . 8 2 3}$ \\
\hline C2 & 0.185 & 0.192 & 0.143 & $\mathbf{0 . 8 5 5}$ \\
\hline PU1 & 0.202 & $\mathbf{0 . 8 7 9}$ & 0.113 & 0.194 \\
\hline PU2 & 0.211 & $\mathbf{0 . 8 8 2}$ & 0.151 & 0.184 \\
\hline PU3 & 0.225 & $\mathbf{0 . 8 4 8}$ & 0.271 & 0.137 \\
\hline S1 & $\mathbf{0 . 7 8 8}$ & 0.243 & 0.282 & 0.297 \\
\hline S2 & $\mathbf{0 . 7 8 4}$ & 0.222 & 0.290 & 0.256 \\
\hline S3 & $\mathbf{0 . 8 6 1}$ & 0.225 & 0.138 & 0.232 \\
\hline S4 & $\mathbf{0 . 6 9 3}$ & 0.295 & 0.383 & 0.236 \\
\hline Cl1 & 0.240 & 0.234 & $\mathbf{0 . 8 3 3}$ & 0.170 \\
\hline Cl2 & 0.246 & 0.157 & $\mathbf{0 . 8 3 8}$ & 0.163 \\
\hline Cl3 & 0.168 & 0.128 & $\mathbf{0 . 7 4 4}$ & 0.303 \\
\hline
\end{tabular}

\begin{tabular}{|l|l|l|l|l|}
\hline \multicolumn{5}{|c|}{ Table 3. Internal Consistency Reliability } \\
\hline & Confirmation & $\begin{array}{l}\text { Perceived } \\
\text { Usefulness }\end{array}$ & Satisfaction & $\begin{array}{l}\text { Continuance } \\
\text { Intention }\end{array}$ \\
\hline Cronbach's $\alpha$ & 0.765 & 0.921 & 0.922 & 0.852 \\
\hline
\end{tabular}

Goodness-of-fit of the CFA model has been assessed using the measures listed in Table 4. Since all thresholds suggested by Hu \& Bentler (1999) were met, an adequate model fit is indicated. Moreover, the standardized residuals among individual scale items ranged between -1.357 and 1.893 and, hence, were - in accordance with the original study - below the recommended threshold value of 3.0.

\begin{tabular}{|l|l|l|}
\hline \multicolumn{3}{|c|}{ Table 4. Goodness of Fit of the CFA Model } \\
\hline Measure & Proposed Threshold & Reached in CFA model \\
\hline$X^{2} / \mathrm{df}$ & $<3$ & $2.186\left(X^{2}=104.941 ; \mathrm{df}=48\right)$ \\
\hline Tucker-Lewis-Index (TLI) & $>0.9$ & 0.972 \\
\hline Comparative Fit Index (CFI) & $>0.9$ & 0.979 \\
\hline RMSEA & $<0.1$ & 0.06 \\
\hline
\end{tabular}

As in the original study, convergent validity was assessed using the three criteria suggested by Fornell and Larcker (1981): (1) all indicator factor loadings $(\lambda)$ should be significant and exceed 0.7, (2) construct reliabilities should exceed 0.8 , and (3) the average variance extracted (AVE) for each construct should exceed the proposed threshold of 0.5 . The results of the CFA indicate that all indicator factor loadings are significant at the $p=0.001$ level and range between 0.701 (Cl3) and 0.912 (PU2). Moreover, the composite reliability (CR) ranges from 0.767 to 0.923 , and the AVE is between 0.622 and 0.796 (see Table 5). Hence, all conditions for convergent validity were met, which indicates an adequate convergent validity for the CFA model.

\begin{tabular}{|l|l|l|l|}
\hline \multicolumn{4}{|c|}{ Table 5. Construct Reliability } \\
\hline Latent Variable & CR & AVE & Highest Squared Correlation \\
\hline Confirmation & 0.767 & 0.622 & 0.461 \\
\hline Perceived Usefulness & 0.921 & 0.796 & 0.368 \\
\hline Satisfaction & 0.923 & 0.751 & 0.461 \\
\hline Continuance Intention & 0.862 & 0.677 & 0.446 \\
\hline
\end{tabular}

To test discriminate validity, the criterion suggested by Fornell and Larcker (1981) has been implemented. This criterion states that the AVE of each latent variable should be greater than the latent variable's highest squared correlation with any other latent variable. The results presented in Table 5 show the requirements are given for all latent variables. 


\subsection{Hypothesis Testing}

The hypotheses postulated in Section 2 were tested using the SEM approach, which was also performed using SPSS AMOS version 24. This approach is in accordance with the original study of Bhattacherjee (2001). Therefore, each indicator was modeled in a reflective manner (as in CFA), the four constructs were linked as hypothesized, and model estimation was determined using the maximum likelihood approach. Referring to the goodness-of-fit, the model's $X^{2}$ /df was $2.186\left(X^{2}=104.941\right.$; $\left.\mathrm{df}=48\right)$, the TLI was 0.972 , the CFI was 0.979 , and the RMSEA was 0.061 . These measures indicate an adequate fit between the hypothesized model and the observed data for the SEM model.

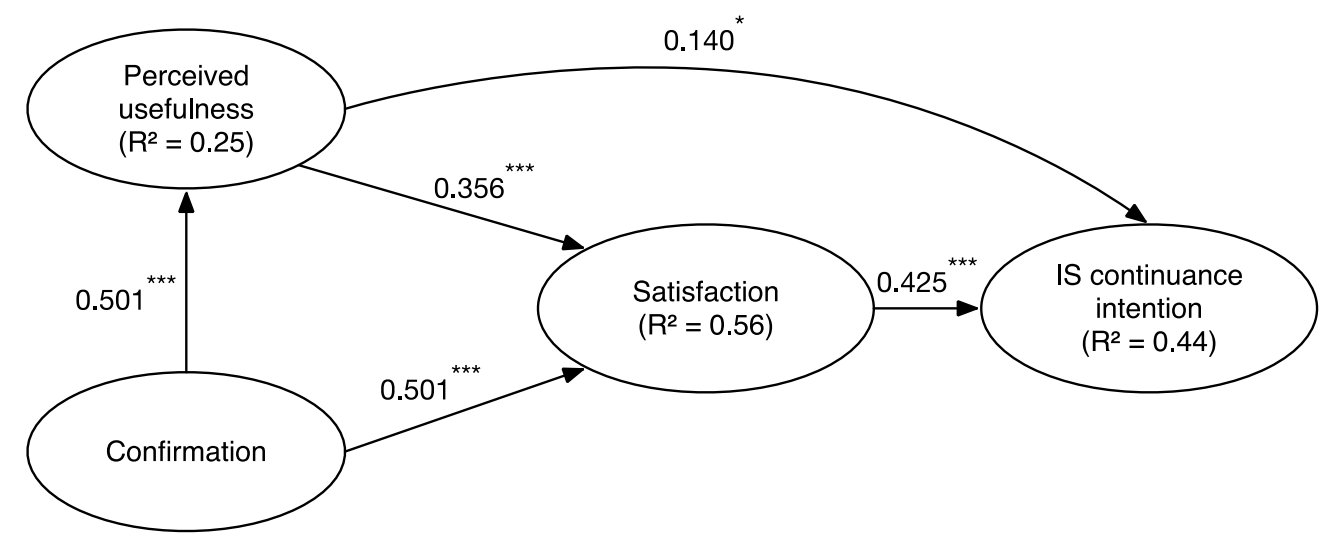

Figure 2. Path Coefficients and Levels of Significance of our Study (Path significance: *** $p<.001,{ }^{* *} p<.01$, * $p<.05$ )

In the following, the path significance and variance explained (R2 value) for each path of the research model were examined. Figure 2 shows the path coefficients and path significances for the SEM model. The paths marked with * are significant at $p<0.05$, whereas the paths with the marker $* \star *$ are significant at $p<0.001$. Hence, all hypotheses postulated in Section 2 are supported.

The construct IS continuance intention was predicted by satisfaction $(\beta=0.425)$ and perceived usefulness $(\beta=0.140)$, which explained $43.9 \%$ of the IS continuance intention variance respectively. Additionally, perceived usefulness had a small indirect effect on IS continuance intention $(\beta=0.151)$ via satisfaction. Satisfaction, in turn, was predicted by confirmation $(\beta=0.501)$ and perceived usefulness $(\beta=0.356)$, which explained $55.6 \%$ of the satisfaction variance. Confirmation also had a small indirect effect on satisfaction via the perceived usefulness construct. Finally, confirmation was a significant predictor of perceived usefulness $(\beta=0.501)$ explaining $25.1 \%$ of the perceived usefulness variance. The results and the corresponding implications of these effects for IS continuance intention are discussed in the following section. A comparison regarding the main characteristics and results of this study and the original study by Bhattacherjee (2001) is shown in Table 6.

\begin{tabular}{|l|l|l|}
\hline \multicolumn{2}{|c|}{ Table 6. Comparison of the Studies' Characteristics and Results } \\
\hline Characteristic & Original Study & This Study \\
\hline Theoretical Foundation & ECT & ECT \\
\hline Context & American banking users & German Dropbox users \\
\hline Number of datasets & 122 & 321 \\
\hline Methodology & EFA, CFA, SEM & EFA, CFA, SEM \\
\hline Analysis Software & EQS & SPSS Amos version 24 \\
\hline Hypothesis Support & All hypotheses supported & All hypotheses supported \\
\hline$R^{2}$ for Continuance Intention & $41 \%$ & $44 \%$ \\
\hline
\end{tabular}

\section{Discussion and Conclusion}

In line with the original study conducted by Bhattacherjee (2001), our methodological replication confirms the validity of the proposed model on IS continuance in a modern context of cloud services, which are subject to positive network effects, low switching costs, and freemium business models. Compared to the original study, our sample is more than twice as large, and the estimated model shows higher goodness- 
of-fit values. In accordance with the original study, perceived usefulness and confirmation show a small indirect effect via the satisfaction construct on IS continuance. Moreover, our analysis indicates satisfaction and perceived usefulness as significant predictors of IS continuance intention, although their path coefficients on IS continuance intention are lower than the original ones $(0.425<0.567$ and $0.140<$ 0.294). However, the construct IS continuance intention is explained by a slightly higher $R^{2}$ value of 0.44 (vs. 0.41 in the original study).

Since our analysis reveals lower path coefficients and a higher $\mathrm{R}^{2}$, further sources of IS continuance intention, which were not embedded in Bhattacherjee's model, are presumed to influence its designated construct in our context. First, existing research suggests that potential divergences might emerge because the intent to continue use of freemium business models in our context may depend on different reasons than for classic, paid applications in the original context (Meuter, Bitner, Ostrom, \& Brown, 2005). Unfortunately, only $2 \%$ of our respondents used the paid model, so we were unable to examine differences in the continuance intention of both customer groups. Further samplings are needed to investigate the influence of both free and charged services on continuance intentions.

Second, we assume that positive network effects are another source of IS continuance intention in our context. Specifically, Dropbox users benefit from an increasing number of users, since the more users Dropbox has, the larger is the group of people with whom each user can share files. The following comment of one of our respondents emphasizes that the sharing of files with other users is one of the most important reasons to use Dropbox: "I am using Dropbox (...) primarily to share university documents, since Dropbox enables (...) the sharing of a huge amount of data." Existing research already found that technology adoption in the context of network effects differs (Katz \& Shapiro, 1994). Hence, we claim for further research considering factors, such as network effects, as explicit sources of IS continuance intention.

Third, we also assume that low switching costs are in effect in our context. Users of file hosting cloud services may continue and discontinue the use of the IS and switch to a competitor at any time with a simple click. Yang and Peterson (2004) also found that switching costs have a moderating effect on satisfaction and perceived usefulness and, thus, also affect IS continuance intention. Hence, we also claim for future research the explicit effects of low switching costs on IS continuance intention.

Our replication study suffers from several limitations, which are also present in the original study. First, Bhattacherjee (2001) stated in the original study that his findings were biased due to the omission of discontinued usage. We tried to integrate those users in our study, but only $2.1 \%$ of the respondents formerly used Dropbox as a cloud service and ended the usage prior to the study. Thus, no reliable conclusions can be drawn regarding differing behaviors in both user groups.

Second, we performed no longitudinal study, although the effects and reasons for continuance intention generally need to be measured over a longer period. Still, most studies that empirically tested the ECM chose a cross-sectional design due to its simplicity (Bhattacherjee \& Barfar, 2011). Thus, differences between the continuance intention and the realized continuance behavior cannot be exposed.

Finally, our study is biased by the sampling, so we cannot guarantee validity for different user groups. The study at hand examines mostly students approximately 23 years of age (median) who are using the free version of Dropbox. Therefore, the respondent group is limited, and the results cannot be generalized because it cannot be guaranteed that other user groups behave in the same way.

In conclusion, the purpose of this study was to methodologically replicate the original work of Bhattacherjee (2001) to confirm the validity of the proposed model on IS continuance in a more modern IS context. Therefore, we conducted a cross-sectional field survey of Dropbox usage in Germany and performed an SEM analysis using 321 samples. This study's results comply with those in the replicated study and, thus, strengthen and generalize the original results to a modern IS context, as characterized by freemium business models, positive network effects, and low switching costs. 


\section{References}

Bhattacherjee, A. (2001). Understanding information systems continuance: An expectation-confirmation model. MIS Quarterly, 25(3), 351-370.

Bhattacherjee, A., \& Barfar, A. (2011). Information technology continuance research: Current state and future directions. Asia Pacific Journal of Information Systems, 21(2), 1-18.

Chiu, C.-M., \& Wang, E. T. (2008). Understanding Web-based learning continuance intention: The role of subjective task value. Information \& Management, 45(3), 194-201.

Davis, F. D. (1985). A technology acceptance model for empirically testing new end-user information systems: Theory and results (Doctoral Dissertation).

Dennis, A. R., \& Valacich, J. S. (2014). A replication manifesto. AlS Transactions on Replication Research, 1(1), 1-4.

Elton, E. J., Gruber, M. J., \& Blake, C. R. (1996). Survivor bias and mutual fund performance. Review of Financial Studies, 9(4), 1097-1120.

Fornell, C., \& Larcker, D. F. (1981). Evaluating structural equation models with unobservable variables and measurement error. Journal of Marketing Research, 18(1), 39-50.

Hu, L., \& Bentler, P. M. (1999). Cutoff criteria for fit indexes in covariance structure analysis: Conventional criteria versus new alternatives. Structural Equation Modeling: A Multidisciplinary Journal, 6(1), 155.

Katz, M. L., \& Shapiro, C. (1994). Systems competition and network effects. The Journal of Economic Perspectives, 8(2), 93-115.

Kumar, V. (2014). Making "freemium" work. Harvard Business Review, 92(5), 27-29.

Limayem, M., Hirt, S. G., \& Cheung, C. M. (2007). How habit limits the predictive power of intention: The case of information systems continuance. MIS Quarterly, 31(4), 705-737.

Lin, C. S., Wu, S., \& Tsai, R. J. (2005). Integrating perceived playfulness into expectation-confirmation model for web portal context. Information \& Management, 42(5), 683-693.

Mathieson, K. (1991). Predicting user intentions: Comparing the technology acceptance model with the theory of planned behavior. Information Systems Research, 2(3), 173-191.

Meuter, M. L., Bitner, M. J., Ostrom, A. L., \& Brown, S. W. (2005). Choosing among alternative service delivery modes: An investigation of customer trial of self-service technologies. Journal of Marketing, 69(2), 61-83.

Oliver, R. L. (1980). A cognitive model of the antecedents and consequences of satisfaction decisions. Journal of Marketing Research, 460-469.

Shapiro, C., \& Varian, H. R. (1999). Information rules: A strategic guide to the network economy. Boston, Mass: Harvard Business School Press.

Spreng, R. A., MacKenzie, S. B., \& Olshavsky, R. W. (1996). A reexamination of the determinants of consumer satisfaction. Journal of Marketing, 60(3), 15-32.

Thong, J. Y., Hong, S.-J., \& Tam, K. Y. (2006). The effects of post-adoption beliefs on the expectationconfirmation model for information technology continuance. International Journal of HumanComputer Studies, 64(9), 799-810.

Vedadi, A., \& Warkentin, M. (2016). Continuance intention on using mobile banking applications: A replication study of information systems continuance model. AIS Transactions on Replication Research, 2(7), 1-11.

Yang, Z., \& Peterson, R. T. (2004). Customer perceived value, satisfaction, and loyalty: The role of switching costs. Psychology \& Marketing, 21(10), 799-822. 


\section{Appendix A: Descriptive Statistics of Respondents}

\begin{tabular}{|c|c|c|c|}
\hline \multicolumn{4}{|c|}{ Table A1. Descriptive Statistics of Respondents $(N=327)$} \\
\hline Measure & Item & Frequency & Percent \\
\hline \multirow{2}{*}{ Gender } & Female & 148 & 45.3 \\
\hline & Male & 179 & 54.7 \\
\hline \multirow{5}{*}{ Formal education } & $\begin{array}{l}\text { Completed } \\
\text { vocational training }\end{array}$ & 7 & 2.1 \\
\hline & $\begin{array}{l}\text { Vocational } \\
\text { diploma }\end{array}$ & 2 & 0.6 \\
\hline & $\begin{array}{l}\text { University- } \\
\text { entrance diploma }\end{array}$ & 191 & 58.4 \\
\hline & University degree & 118 & 36.1 \\
\hline & Other & 9 & 2.8 \\
\hline \multirow{7}{*}{ Job } & Apprentice & 1 & 0.3 \\
\hline & Student & 289 & 88.4 \\
\hline & Employee & 21 & 6.4 \\
\hline & Official & 9 & 2.8 \\
\hline & Self-employed & 5 & 1.5 \\
\hline & Unemployed & 1 & 0.3 \\
\hline & Other & 1 & 0.3 \\
\hline \multirow{8}{*}{ Monthly income } & $\mathrm{N} / \mathrm{A}$ & 26 & 8.0 \\
\hline & No own income & 41 & 12.5 \\
\hline & $<250 €$ & 21 & 6.4 \\
\hline & $250 €-499 €$ & 82 & 25.1 \\
\hline & $500 €-999 €$ & 86 & 26.3 \\
\hline & $1,000 €-1,499 €$ & 44 & 13.5 \\
\hline & $1,500 €-1,999 €$ & 8 & 2.4 \\
\hline & $\geq 2,000 €$ & 19 & 5.8 \\
\hline \multirow{6}{*}{ Use of cloud service providers } & Dropbox & 320 & 97.9 \\
\hline & iCloud & 113 & 34.6 \\
\hline & OneDrive & 84 & 25.7 \\
\hline & Google Drive & 103 & 31.5 \\
\hline & Box & 3 & 0.9 \\
\hline & Others & 29 & 8.9 \\
\hline
\end{tabular}

\section{Appendix B: Translated Construct Measurements}

\begin{tabular}{|c|c|c|}
\hline \multicolumn{3}{|c|}{ Table B1. Translated Construct Measurements } \\
\hline Construct & Measurement Item (translated) & Adapted from \\
\hline Confirmation (C) & & \multirow{4}{*}{$\begin{array}{l}\text { Bhattacherjee } \\
\quad(2001)\end{array}$} \\
\hline C1 & $\begin{array}{l}\text { Meine Erfahrungen mit dem Gebrauch von } \\
\text { Dropbox waren besser als erwartet. }\end{array}$ & \\
\hline $\mathrm{C} 2$ & $\begin{array}{l}\text { Der Service von Dropbox war besser als } \\
\text { erwartet. }\end{array}$ & \\
\hline C3 & $\begin{array}{lccc}\text { Insgesamt wurden die meisten } & \text { meiner } \\
\text { Erwartungen an Dropbox erfüllt. } & \\
\end{array}$ & \\
\hline \multicolumn{2}{|c|}{ Perceived Usefulness (PU) } & \multirow{5}{*}{$\begin{array}{l}\text { Davis } \\
(1989)\end{array}$} \\
\hline PU1 & $\begin{array}{l}\text { Die Nutzung von Dropbox verbessert meine } \\
\text { Leistungsfähigkeit bei der Verwaltung meiner } \\
\text { Dateien. }\end{array}$ & \\
\hline PU2 & $\begin{array}{l}\text { Die Nutzung von Dropbox erhöht meine } \\
\text { Produktivität bei der Verwaltung meiner Dateien. }\end{array}$ & \\
\hline PU3 & $\begin{array}{l}\text { Die Nutzung von Dropbox fördert meine } \\
\text { Effektivität bei der Verwaltung meiner Dateien. }\end{array}$ & \\
\hline PU4 & $\begin{array}{l}\text { Insgesamt sehe ich Dropbox als nützliches Tool } \\
\text { für die Verwaltung meiner Dateien }\end{array}$ & \\
\hline Satisfaction (S) & $\begin{array}{l}\text { Wie denken Sie über ihre Erfahrungen mit der } \\
\text { Nutzung von Dropbox? }\end{array}$ & \multirow{2}{*}{$\begin{array}{l}\text { Spreng et al. } \\
\quad(1996)\end{array}$} \\
\hline S1 & Sehr unzufrieden/Sehr zufrieden & \\
\hline
\end{tabular}




\begin{tabular}{|l|l|c|}
\hline S2 & Sehr verärgert/Sehr erfreut & \\
\hline S3 & Sehr frustriert/Hochzufrieden & \\
\hline S4 & Überhaupt nicht überzeugt/Sehr überzeugt & \\
\hline IS Continuance Intention (IS) & \multicolumn{1}{|c|}{} & \\
\cline { 1 - 2 } Cl1 & $\begin{array}{l}\text { Ich habe vor Dropbox weiterhin zu nutzen, } \\
\text { anstatt die Nutzung einzustellen. }\end{array}$ & \multirow{2}{*}{$\begin{array}{c}\text { Mathieson } \\
\text { (1991) }\end{array}$} \\
\cline { 1 - 2 } Cl2 & $\begin{array}{l}\text { Ich möchte Dropbox weiterhin nutzen, anstatt auf } \\
\text { ein alternatives Produkt umzusteigen. }\end{array}$ & \\
\cline { 1 - 2 } Cl3 & $\begin{array}{l}\text { Wenn ich könnte, würde ich Dropbox nicht mehr } \\
\text { nutzen. }\end{array}$ & \\
\hline
\end{tabular}

\section{Appendix C: Descriptive Statistics of Measurements}

\begin{tabular}{|l|l|l|l|l|}
\hline \multicolumn{5}{|c|}{ Table C1. Descriptive Statistics $(N=312)$} \\
\hline $\begin{array}{l}\text { Latent } \\
\text { Variable }\end{array}$ & Mean & $\begin{array}{l}\text { Standard } \\
\text { Deviation }\end{array}$ & Minimum & Maximum \\
\hline Cl1 & 5.795 & 1.374 & 1 & 7 \\
\hline C12 & 5.193 & 1.500 & 1 & 7 \\
\hline Cl3 & 5.542 & 1.524 & 1 & 7 \\
\hline S1 & 5.651 & 1.085 & 1 & 7 \\
\hline S2 & 5.514 & 1.168 & 1 & 7 \\
\hline S3 & 5.449 & 1.103 & 1 & 7 \\
\hline S4 & 5.670 & 1.169 & 1 & 7 \\
\hline PU1 & 4.925 & 1.490 & 1 & 7 \\
\hline PU2 & 5.022 & 1.534 & 1 & 7 \\
\hline PU3 & 5.109 & 1.482 & 1 & 7 \\
\hline PU4 & 5.850 & 1.141 & 1 & 7 \\
\hline C1 & 4.969 & 1.199 & 1 & 7 \\
\hline C2 & 4.483 & 1.115 & 1 & 7 \\
\hline C3 & 5.648 & 0.999 & 2 & 7 \\
\hline
\end{tabular}

\section{Appendix D: Initial Rotated Component Matrix}

\begin{tabular}{|l|l|l|l|l|}
\hline \multicolumn{5}{|c|}{ Table D1. Initial Rotated Component Matrix } \\
\hline \multicolumn{5}{|l|}{ Component } \\
\cline { 2 - 5 } & $\mathbf{1}$ & $\mathbf{2}$ & $\mathbf{3}$ & $\mathbf{4}$ \\
\hline S3 & $\mathbf{0 . 8 5 4}$ & 0.222 & 0.133 & 0.240 \\
\hline S1 & $\mathbf{0 . 7 8 6}$ & 0.245 & 0.283 & 0.308 \\
\hline S2 & $\mathbf{0 . 7 7 4}$ & 0.216 & 0.281 & 0.263 \\
\hline S4 & $\mathbf{0 . 6 8 7}$ & 0.299 & 0.384 & 0.242 \\
\hline C3 & $\mathbf{0 . 4 5 1}$ & 0.320 & 0.374 & 0.358 \\
\hline PU2 & 0.203 & $\mathbf{0 . 8 7 9}$ & 0.145 & 0.191 \\
\hline PU1 & 0.194 & $\mathbf{0 . 8 7 4}$ & 0.105 & 0.200 \\
\hline PU3 & 0.220 & $\mathbf{0 . 8 4 4}$ & 0.264 & 0.147 \\
\hline PU4 & 0.388 & $\mathbf{0 . 5 0 5}$ & 0.433 & 0.239 \\
\hline Cl1 & 0.234 & 0.235 & $\mathbf{0 . 8 3 1}$ & 0.178 \\
\hline Cl2 & 0.239 & 0.150 & $\mathbf{0 . 8 2 9}$ & 0.172 \\
\hline Cl3 & 0.160 & 0.126 & $\mathbf{0 . 7 3 9}$ & 0.308 \\
\hline C2 & 0.173 & 0.185 & 0.133 & $\mathbf{0 . 8 5 7}$ \\
\hline C1 & 0.216 & 0.117 & 0.231 & $\mathbf{0 . 8 2 6}$ \\
\hline
\end{tabular}

\section{Appendix E: SEM Analysis without Item Drop}

\begin{tabular}{|l|l|l|}
\hline \multicolumn{3}{|c|}{ Table E1. Goodness of Fit of the CFA Model (Without Item Drop) } \\
\hline Measure & Threshold & Reached in CFA model \\
\hline $\mathrm{X}$ 2/df & $<3$ & $3.995(\mathrm{X} 2=283.641 ; \mathrm{df}=34)$ \\
\hline Tucker-Lewis-Index $(\mathrm{TLI})$ & $>0.9$ & 0.917 \\
\hline Comparative Fit Index (CFI) & $>0.9$ & 0.935 \\
\hline RMSEA & $<0.1$ & 0.097 \\
\hline
\end{tabular}




\begin{tabular}{|l|l|l|l|}
\hline \multicolumn{3}{|c|}{ Table E2. Construct Reliability (Without Item Drop) } \\
\hline Latent Variable & CR & AVE & $\begin{array}{l}\text { Highest Squared } \\
\text { Correlation }\end{array}$ \\
\hline Confirmation & 0.675 & 0.511 & 0.684 \\
\hline Perceived Usefulness & 0.905 & 0.707 & 0.404 \\
\hline Satisfaction & 0.923 & 0.750 & 0.684 \\
\hline Continuance Intention & 0.862 & 0.677 & 0.513 \\
\hline
\end{tabular}

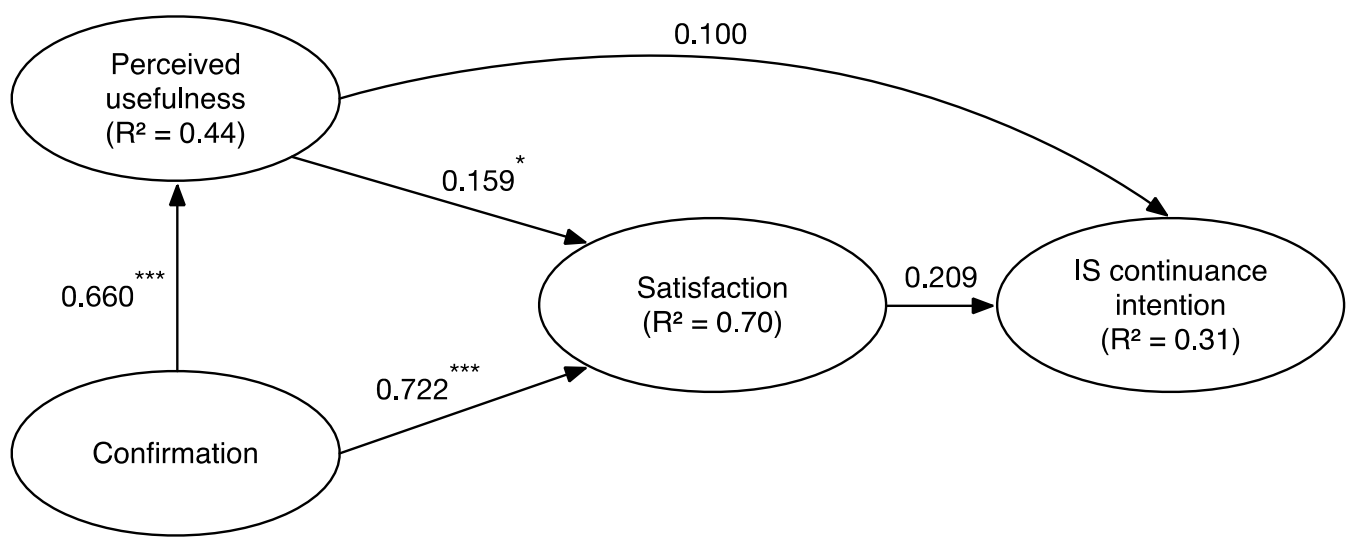

Figure E1. Path Coefficients and Levels of Significance (Without Item Drop)

(Path significance: *** $p<.001$, ** $p<.01$, * $p<.05$ )

Note: Paths marked without an asterisk are significant at $p<0.15$ 


\section{About the Authors}

Pascal Budner is a graduate student in Information Systems at the University of Cologne, where he also obtained his undergraduate degree in Business Informatics. Besides his studies, he works as a software developer and is particularly interested in the fields of data science and network science.

Mareike Fischer is a graduate student in Information Systems at the University of Cologne. She holds a B.Sc. degree in Business Informatics and works as a student assistant at the Institute for Information Systems, University of Cologne.

Christoph Rosenkranz is Full Professor of Information Systems at University of Cologne. He holds Diploma and doctoral degrees from the University of Münster and Goethe University, respectively. His research focuses on integrated information systems as socio-technical systems, business process management, information systems development and IT project management, and online communities. He has published articles in such outlets as ACM Transactions on Management Information Systems, Business \& Information Systems Engineering, European Journal of Information Systems, Information Systems Journal, Journal of Database Management, Journal of Information Technology, and Journal of the Association for Information Systems.

Dirk Basten is an Assistant Professor at the Department of Information Systems and Systems Development at the University of Cologne, Germany. His research focuses on IS project success, software development effort estimation, knowledge management in project and program contexts, and Gamification. His research has been published in journals such as Project Management Journal, Journal of Computer Information Systems, Communications of the Association for Information Systems, IEEE Computer, IEEE Software, International Journal of Information Technology Project Management, and the proceedings of conferences such as HICSS, ECIS, AMCIS, and ICIS.

Lars Terlecki studies Information Systems M.Sc. as a graduate student at the University of Cologne and works as a data science consultant. He has a B.Sc. in Business Information Systems (2015) and is especially interested in business intelligence and data science.

Copyright $\odot 2017$ by the Association for Information Systems. Permission to make digital or hard copies of all or part of this work for personal or classroom use is granted without fee provided that copies are not made or distributed for profit or commercial advantage and that copies bear this notice and full citation on the first page. Copyright for components of this work owned by others than the Association for Information Systems must be honored. Abstracting with credit is permitted. To copy otherwise, to republish, to post on servers, or to redistribute to lists requires prior specific permission and/or fee. Request permission to publish from: AIS Administrative Office, P.O. Box 2712 Atlanta, GA, 30301-2712 Attn: Reprints or via email from ais@aisnet.org. 